\title{
The effect of gas pressure during ion-plasma deposition on the microstructure of M-coatings and the emission properties of molecular sputter-deposited oxide cathodes
}

\author{
Gennady Zhabin ${ }^{1, *}$ and Denis Arkhipov ${ }^{1}$ \\ ${ }^{1}$ JSC «RPC «Istok» named after Shokin», st. Vokzalnaya, 2A, Fryazino, Moscow Region, 141190, \\ Russia
}

\begin{abstract}
The results of the study of the effect of gas pressure and gas composition by ion-plasma deposition of oxide coatings on the microstructure and the emission properties of molecular sputter-deposited oxide cathodes (MSDOC) are presented. Scanning electron microscopy (SEM) with an energy-dispersive spectrometer (EDS) and atomic force microscopy (AFM) has been used to investigate changes in the morphology, microstructure, and elemental composition of the films. It is shown that with decreasing pressure, the emission properties of films improve, the coating density and grain size increase, and the roughness decreases.
\end{abstract}

\section{Introduction}

In vacuum microwave devices based on cyclotron resonance - cyclotron protective devices (CPD), molecular sputter-deposited oxide cathodes (MSDOC) with an emission area of $1.4 \cdot 10^{-4} \mathrm{~cm}^{2}$ are used as a thermionic emitter [1,2]. Applying an emission coating (M-coating) with a thickness of $0.8-1 \mu \mathrm{m}$ occurs in vacuum using ion-plasma sputtering from a target with a composition of $(\mathrm{BaCaSr}) \mathrm{CO}_{3}$ with a grain size of $1-2 \mu \mathrm{m}$ [2-4]. The grain size of the precipitated M-coating of MSDOC is from 10 to $100 \mathrm{~nm}[4,5]$. It is known that reducing the grain size of solids to several tens of nanometers significantly changes their bulk properties [6]. The use of the ion-plasma method of deposition of M-coating on the surface of the core MSDOC allows to significantly increase the density of the oxide coating (up to $3.9-4.5 \mathrm{~g} / \mathrm{cm}^{3}$ ), increase the electrical conductivity and emission current density, reduce the operating temperature of the cathodes compared to oxide cathodes, manufactured according to standard technology $[2,3]$.

When manufacturing MSDOCs there is no need to use a binder. The influence of changes in the parameters of ion-plasma deposition of M-coatings on the chemical composition and emission properties of MSDOC is not sufficiently studied [4, 7]. In order to further improve the emission and operational parameters of the CPD with the use of an MSDOC, it is necessary to study the effect of working gas pressure on the structure of Mcoatings and the emission properties of cathodes.

${ }^{*}$ Corresponding author: zhabingennady@yandex.ru 
This paper presents the results of a study of the influence of the working gas pressure on the microstructure of M-coatings and the emission properties of MSDOC used in the CPD.

\section{Experimental methods}

The objects of research were polished samples of silicon KEF-18 and foil from alloy WRe27 with a thickness of $50 \mu \mathrm{m}$ and a size of $0.5 \times 0.5 \mathrm{~mm}$ and cathodes. The samples were previously chemically treated from organic contaminants. In the sputtering unit, the samples and cathodes located at a distance of 33-36 $\mathrm{mm}$ from the center of the plasma column were deposited on with M-coatings from a target of standard composition $(\mathrm{BaSrCa}) \mathrm{CO}_{3}$ with a ratio of $\mathrm{AEM}$ atoms: $47 \% \mathrm{Ba}, 43 \% \mathrm{Sr}, 10 \% \mathrm{Ca}$. The cathodes had a heater of WRe-27 and a core with iridium film. The emission area of cathodes was $1.4 \cdot 10^{-4}$ $\mathrm{cm}^{2}$. The base pressure in the sputtering unit after the decomposition of the carbonates of the target before the inlet of the working mixture had a value of $4.2 \cdot 10^{-4} \mathrm{~Pa}$. The rate of gas pumping from the vacuum system was about $500 \mathrm{l} / \mathrm{s}$. The thickness of the M-coatings was 0.8-1 $\mu \mathrm{m}$ at three different modes of pressure of the working gas (a mixture of $\mathrm{Ar}+\mathrm{CO}_{2}$ or $\mathrm{Xe}+\mathrm{CO}_{2}$ ). The $\mathrm{CO}_{2}$ content in the working gas mixture was about $45-50 \%$. The discharge power during the deposition in the constant current mode was equal to $160 \mathrm{~W}$. The deposition of the M- coating onto the cathodes was carried out in a magnetic field with a direct current on the target, with the substrate potential equal to 0 .

The distance between the sprayed target and the samples was about $20 \mathrm{~mm}$. The target temperature, measured by an optical pyrometer, rose during deposition to $750-760{ }^{\circ} \mathrm{C}$. The temperature of the fixed copper substrate during the deposition was $175-220{ }^{\circ} \mathrm{C}$. The substrate temperature was measured using a thermocouple. Vacuum measurement during deposition of coatings was carried out using a vacuum gauge VMB-14, manufactured in Russia. The deposition of M-coating on the cathodes and samples was carried out in three pressure modes of the mixture of gases.

When deposited in the first mode, the working pressure of the gas mixture $\mathrm{Xe}+\mathrm{CO}_{2}$ was 0.11-0.13 $\mathrm{Pa}$. In the second deposition mode, the working pressure of the $\mathrm{Ar}+\mathrm{CO}_{2}$ gas mixture was $0.1 \mathrm{~Pa}$. In the third mode, the working pressure of the $\mathrm{Xe}+\mathrm{CO}_{2}$ gas mixture was $0.075-0.08 \mathrm{~Pa}$.

The elemental analysis of M-coatings was determined by X-ray spectral microanalysis (RSMA) method, using the INCA Penta FET x 3 energy dispersive spectrometer (EDS) from Oxford Instruments (United Kingdom) as an attachment to the SEM. Surface areas up to $100 \times 100$ microns in size were investigated. The surface morphology was investigated by high-resolution SEM with the field emission cathode JSM 7500, manufactured by JEOL (Japan) and AFM by AIST-NT (Russia).

The emission properties of MSDOCs were studied on mock-ups of microwave devices at the thermal training stand using the standard procedure $[2,4]$. The distance between the cathode and the anode was $100 \mu \mathrm{m}$. The level of residual gases in the mock-ups after the pumping operation was no more than $10^{-6} \mathrm{~Pa}$. According to the test results, the emission characteristics of MSDOC were plotted (Fig. 4 (c)).

\section{Results}

Figures 1-3 show the results of studying the surface microstructure of M-coatings $(b, c)$ and cross-section (a) by SEM methods (a, b) and AFM (c).

A comparative analysis of the results showed that the microstructure of M-coatings on the surface and in cross section varies with changes in the pressure of the working gas.

At the micro level, the coating of samples in mode 1 in Fig. 1 is looser than the samples in mode 2 in fig. 2, and its cross section has a «columnar» structure. The cross section of M-coating of the samples in Fig. 2 has a «transitional» structure. 
a

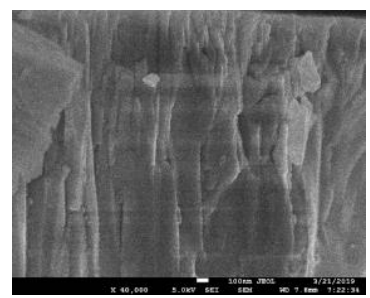

b

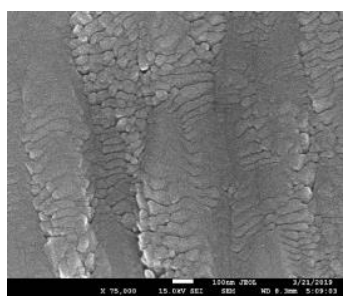

c

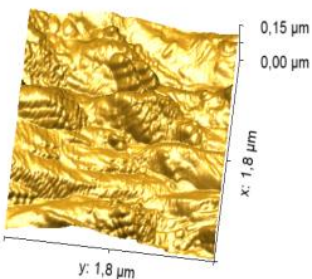

Fig. 1. SEM-image of the cross-section (a) and the surface (b) of the M-coating on the substrate of the WRe-27 plate. AFM image of the M-coating surface on a Si plate (c). The working pressure of the gas mixture $\mathrm{Xe}+\mathrm{CO}_{2}-0.11-0.13 \mathrm{~Pa}$.

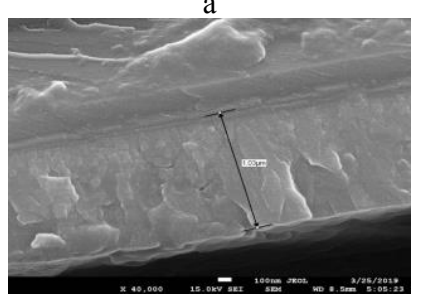

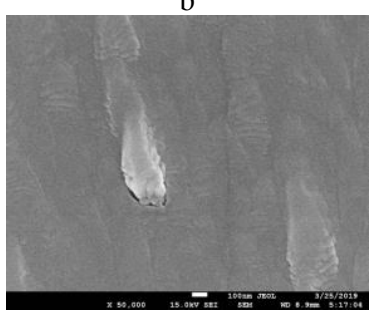

$\mathrm{c}$

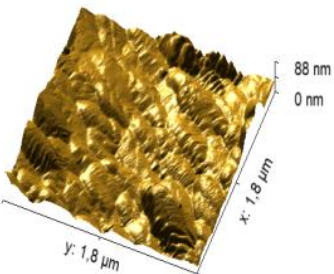

Fig. 2. SEM-image of the cross-section (a) and the surface (b) of the M-coating on the Si substrate. AFM image of the M-coating surface on $\mathrm{Si}(\mathrm{c})$. The working pressure of the gas mixture $\mathrm{Ar}+\mathrm{CO}_{2}$ $-0.1 \mathrm{~Pa}$

a

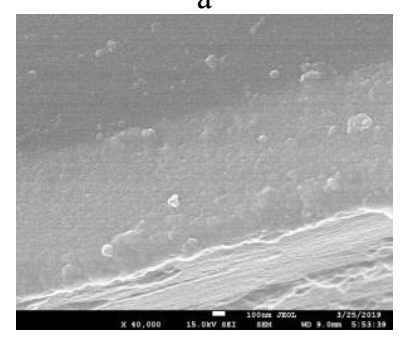

b

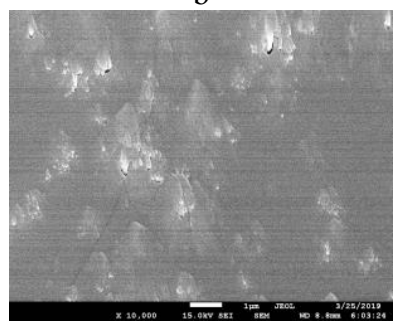

$\mathrm{c}$

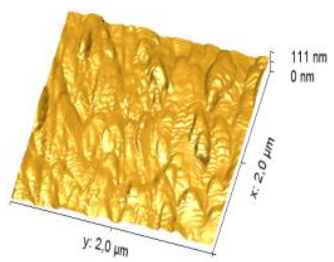

Fig. 3. SEM-image of the cross-section (a) and the surface (b) of the M-coating on the Si substrate. AFM image of the M-coating surface on $\mathrm{Si}(\mathrm{c})$. The working pressure of the gas mixture $\mathrm{Xe}+\mathrm{CO}_{2}$ $-0.075-0.08 \mathrm{~Pa}$

The densest one is the coating of samples in mode 3 in fig. 3. In all samples, through pores are not detected. An AFM study revealed that with increasing pressure of the working gas during the deposition of the M-coating, the «ridges» on the surface increase, the density of the coating decreases.

The RSMA method showed that the elemental composition of M-coatings is not the same. The ratio of the mass. \% Ba: $\mathrm{Sr}$ : Ca was for sample No. 1 in Figure $1-40: 23: 2$; for sample number 2 in fig. $2-35$ : 9.6: 1.9; for sample number 3 in fig. $3-29$ : 15: 1.8 . 
a

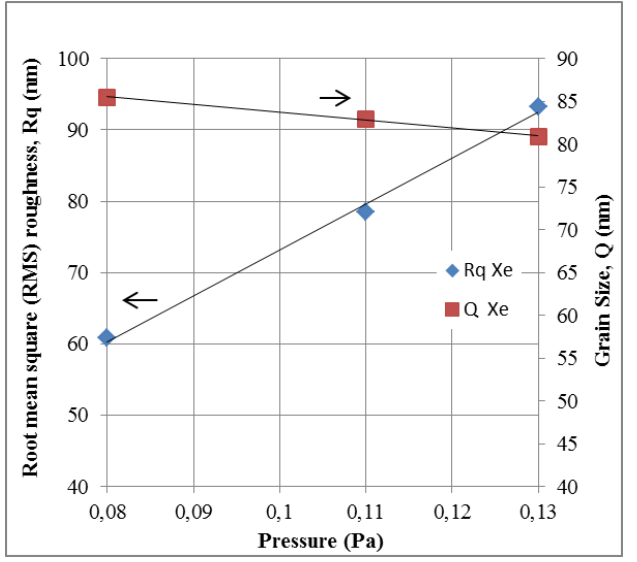

b

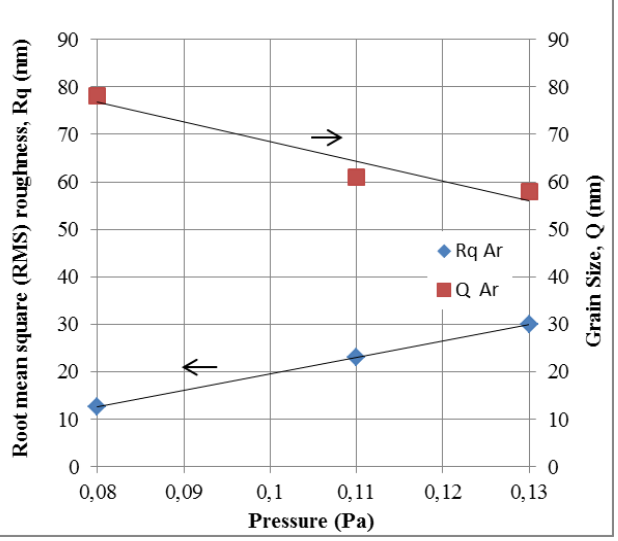

Fig. 4. Plots of roughness $(\mathrm{Rq})$ and grain size $(\mathrm{Q})$ dependencies on the pressure of the working gas mixture with $\left(\mathrm{Xe}+\mathrm{CO}_{2}\right)$ (a) and $\left(\mathrm{Ar}+\mathrm{CO}_{2}\right)(\mathrm{b})$.

Using the Gwyddion program [8] for analyzing AFM images, we obtained results on the grain size $(\mathrm{Q})$ and root mean square roughness $(\mathrm{Rq})$ of $\mathrm{M}$-coatings deposited at different pressures of the working gas. According to the measurement results, graphs of roughness and grain size versus pressure were plotted for a mixture of gas with Xe and Ar (Fig. 4 a, b).

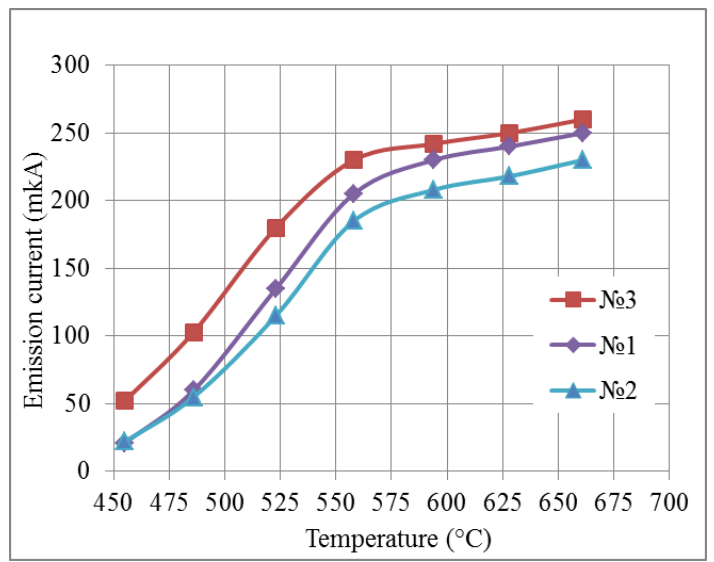

Fig. 5. Emission characteristics of a MSDOC with M-coating deposited at different pressures of the working gas, Pa: No. $1\left(\mathrm{Xe}+\mathrm{CO}_{2}-0.11-0.13\right)$, No. $2\left(\mathrm{Ar}+\mathrm{CO}_{2}-0.1\right)$, No. $3\left(\mathrm{Xe}+\mathrm{CO}_{2}-\right.$ 0.075-0.08).

From Fig. 4 it follows that with decreasing gas pressure, the M-coating roughness decreases. This is due to the fact that the free path length and the energy of the particles deposited on the substrate increases. An increase in the particle energy leads to an increase in the grain size and density of the M-coating.

The effect of pressure on the M-coating structure is associated with a change in the mode of the atoms motion between the sputtered target and the substrate and the mechanism of nucleation on the surface of the coating [9]. 


\section{Discussion}

At high pressures and low $\mathrm{M}$-coating deposition rates $(\mathrm{P}=0.13-0.15 \mathrm{~Pa})$, the chemical and physical interaction of condensing target atoms with the atoms of the working gas increases. Scattering of the sputtered particles by gas atoms increases, which reduces the migration mobility of adatoms and creates conditions for the formation of pores. Due to the presence of pores, the density of the films decreases. In the conditions of long spraying by deposited particles the pores are filled. The cross section of the film has a columnar microstructure with filled pores [10].

At a pressure $(\mathrm{P}=0.11-0.13 \mathrm{~Pa})$ a film deposition occurs under conditions of a higher mobility of adatoms. The microstructure of the coating consists of columns that are no longer separated by pores but by grain boundaries [10]. The grain size of the M-coating was 58-61 nm for a mixture of gases with argon and about 81-83 nm for a mixture of gases with xenon. The root mean square roughness of the coating was $78-93 \mathrm{~nm}$ for a mixture with xenon and 23-30 $\mathrm{nm}$ for a mixture with argon.

At moderate deposition rates $(\mathrm{P}=0.087-0.1 \mathrm{~Pa})$, M-coatings have a «transition» structure.

At high deposition rates $(\mathrm{P}=0.075-0.08 \mathrm{~Pa}), \mathrm{M}$-coatings have a dense structure. With decreasing pressure of the working gas, the free path of the sprayed particles increases. This leads to an increase in the energy and migration mobility of adatoms on the surface of the substrates and an increase in the grain size to $78 \mathrm{~nm}$ when sputtering in a mixture with argon and up to $85 \mathrm{~nm}$ when sputtering in a mixture with xenon. The roughness of the coating is $60 \mathrm{~nm}$ for a mixture with xenon and $12 \mathrm{~nm}$ for a mixture with argon. With an increase in the deposition rate, the content of carbon atoms in the M-coating increases.

From the analysis of M-coatings using SEM and AFM, one can see that during sputtering in an atmosphere with Ar, the M-coating has a finer grain compared to that in an atmosphere of Xe. It is known that with a fine-grained film, the resistivity increases [11].

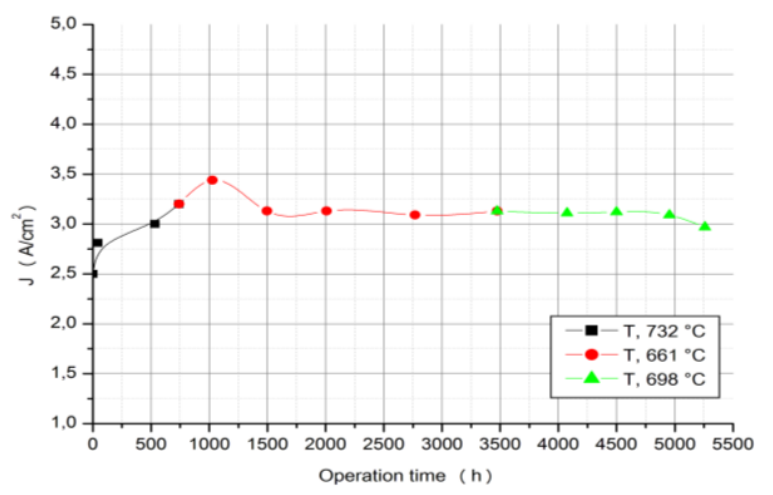

Fig. 6. Plot of current density $\mathrm{J}\left(\mathrm{A} / \mathrm{cm}^{2}\right)$ as a function of the time $\mathrm{t}(\mathrm{h})$ of the MSDOC with Mcoating deposited at the working gas pressure $\left(\mathrm{Xe}+\mathrm{CO}_{2}\right)-0.075-0.08 \mathrm{~Pa}$; $\mathrm{T}$ is the work temperature of the MSDOC, ${ }^{\circ} \mathrm{C}$.

Fig. $4(\mathrm{a}, \mathrm{b})$ shows plots of dependences of the root mean square roughness and grain size on pressure. In fig. 5, the emission characteristics of an MSDOC with an M-coating deposited at different pressures of the working gas were plotted.

The ratio of atomic concentrations of $\mathrm{Ba} / \mathrm{Sr}$ for samples No. 1,2 and 3 is $1.1 ; 2.3 ; 1.2$ respectively.

Despite the increased content of Ba atoms in sample No. 2, the emission current of the MSDOC from this sample is the lowest. This is due to the fact that, in addition to the content of active alkaline earth metals, the concentration of carbon atoms in the coating 
affects the emission properties of MSDOC. It was shown above that with increasing carbonization of the M-coating, its hydration in air decreases, and the emission activity of MSDOC increases [5].

From fig. 5 it follows that the cathodes of sample No. 3 with a denser coating, with a high carbon content, deposited in an atmosphere of $\mathrm{Xe}+\mathrm{CO}_{2}$ at a pressure of $0.075-0.08$ $\mathrm{Pa}$, have the best emission characteristics.

Tests on the durability of MSDOC with a coating thickness of $1.2 \mu \mathrm{m}$ deposited at a working gas pressure $\left(\mathrm{Xe}+\mathrm{CO}_{2}\right)-0.075-0.08 \mathrm{~Pa}$ showed that the cathode service life with a current density of $3 \mathrm{~A} / \mathrm{cm}^{2}$ in continuous mode was more than 5000 hours (Fig. 6).

Thus, the deposition of M-coatings in a mixture with xenon at a pressure of 0.075-0.08 $\mathrm{Pa}$ is the preferred mode, since in this case the emission properties are improved, and the speed and purity of the deposition process increases.

\section{Conclusions}

It is shown that changes in the pressure and composition of the working gas during the deposition of M-coatings effect the microstructure and emission properties of MSDOC.

The dependences of the roughness and grain size of the M-coating on the pressure and gas composition during ion-plasma spraying are obtained. The density of the M-coating and the lateral size of the grains increase with decreasing pressure of the working gas, and the roughness decreases. M-coating obtained in a mixture with Ar has a finer grain compared to sputtering in a mixture with $\mathrm{Xe}$. The elemental analysis showed that M-coatings synthesized at lower gas pressure have a high content of carbon atoms. Cathodes with a denser M-coating, deposited in $\mathrm{Xe}+\mathrm{CO}_{2}$ atmosphere at a pressure of 0.075-0.08 $\mathrm{Pa}$, have the best emission properties.

\section{References}

1. U. A. Budzinsky, S. V. Bykovsky, I. I. Golenitsky, V. G. Kalina, Elektronnaya tekhnika. Ser. 1. Svch-tekhnika. Vol. 3 (518). pp. 136-142 (2013)

2. G. A. Zhabin, Elektronnaya tekhnika. Ser. 1. Svch-tekhnika. Vol. 2 (533). pp. 49-53 (2017).

3. B. P. Nikonov, Oxide cathode (Izd. Energia, Moscow, 1979) [in Russian]

4. G. A. Zhabin, Z. M. Magamednebiev, A. N. Pashkov, Elektronnaya tekhnika. Ser. 1. Svchtekhnika. Vol. 3 (538). pp. 50-58 (2018)

5. G. A. Zhabin, M.V. Zlygostov, in Proc. Elektronika i mikroelektronika svch, (Saint Petersburg, Russia, June 10-16, 2019), pp. 112-116

6. A. I. Gusev, Nanomaterials, Nanostructures, and Nanotechnologies (Fizmatlit, Moscow, 2005)

7. Yan Liu, Christopher M. Day, Scott A. Little, Feng Jin, Thin film deposition of barium strontium oxide by rf magnetron sputtering, J. Vac. Sci. Technol. A 24(6), pp. 2187 - 2191 (2006)

8. Gwyddion - Free SPM (AFM, SNOM/NSOM, STM, MFM ) data analysis software. [2019]. URL: http://www.gwyddion.net/documentation/user-guide-ru

9. A. S. Dzhumaliev, Yu. V. Nikulin, and Yu. A. Filimonov, Effect of the Pressure of Working Gas on the Microcrystalline Structure and Magnetic Properties of the Co Film Deposited with the Aid of Magnetron Sputtering, Radiotekhnika i Elektronika, Vol. 63, No. 1, pp. 90-96 (2018)

10. S. Mahieu, P. Ghekiere, D. Depla, R. De Gryse, Thin Solid Films, 515 (2006), pp. 1229-1249.

11. B. C. Danilin, Application of low-temperature plasma for deposition of thin films (Izd. Energoatomizdat, Moscow, 1989) [in Russian]

12. G. A. Zhabin, D. Yu. Arkhipov, and M. P. Temiryazeva, Pricl. Fiz., No. 5, 54 (2019) 